\title{
Effects of Medical and Nutritional Program on Pulmonary Tuberculosis Treatment Outcome Among Detainees in the Prison of Bertoua, Cameroon (2016-2018)
}

\author{
Linjouom Nchoutpouen Abdou Aziz ${ }^{1,2, *}$, Assob Nguedia Jules Clément ${ }^{1}$, Chichom Mefire Alain ${ }^{3}$, \\ Bessong Joseph Bessong ${ }^{1}$, Njajou Tchikamgoua Omer ${ }^{4}$ \\ ${ }^{1}$ Department of Public Health and Hygiene, Faculty of Health Sciences, University of Buea, Buea, Cameroon \\ ${ }^{2}$ Contract Development and Verification Agency of West Regional Fund for Health Promotion, Bafoussam, Cameroon \\ ${ }^{3}$ Department of Surgery and Obs/Gyn, Faculty of Health Sciences, University of Buea, Buea, Cameroon \\ ${ }^{4}$ School of Public Health, University of Minnesota, Minnesota, USA
}

Email address:

linabdoul@yahoo.fr(L. N. A. Aziz)

${ }^{*}$ Corresponding author

\section{To cite this article:}

Linjouom Nchoutpouen Abdou Aziz, Assob Nguedia Jules Clément, Chichom Mefire Alain, Bessong Joseph Bessong, Njajou Tchikamgoua Omer. Effects of Medical and Nutritional Program on Pulmonary Tuberculosis Treatment Outcome Among Detainees in the Prison of Bertoua, Cameroon (2016-2018). Central African Journal of Public Health. Vol. 5, No. 6, 2019, pp. 237-245. doi: 10.11648/j.cajph.20190506.12

Received: September 1, 2019; Accepted: September 27, 2019; Published: October 10, 2019

\begin{abstract}
This retrospective and cross-sectional study in the Bertoua prison, which has benefited from the International Committee of the Red Cross (ICRC) medical and nutrition program since 2015, assesses its effect in improving the therapeutic success rates of anti-TB treatments compared to that of Douala, not beneficiary and chosen as a witness. There was an exhaustive collection of new and old TB cases diagnosed at entry, before or during incarceration between January $1^{\text {st }}$ and December $31^{\text {st }}$, 2018. Of the 975 and 3300 people incarcerated on average during this period Bertoua and Douala prisons, 27 cases and 79 cases of TB were recorded. The diagnosis of the cases was made according to the good clinical practices recommended by the National Tuberculosis Control Program (NTCP). At the delivery of the results only $37.0 \%$ and $6.6 \%$ of these screened detainees were put on treatment on the first day and some later $(\mathrm{p}<0.05)$. Of the 23 and 51 new cases in 2018,14 and 47 patients were put on a 6month anti-tuberculosis treatment in the first two quarters, 2 cases $(14.3 \%)$ and 14 cases $(29.8 \%)$ did not experience therapeutic success ( $\mathrm{p}<0.05$ ). Moreover, with $85.20 \%$ of new cases in Bertoua prison compared to 64.5\% in Douala prison in 2018 ( $\mathrm{p}<0.1$ ), there are more unhealed patients after treatment than in Bertoua in 2018. In 2016 and 2017, we cannot conclude. From the above, this program must be generalized. It is also necessary to develop and use new, more practical diagnostic methods, to systematize the screening of prisoners in general and at risk, to perform treatment more quickly after screening, to improve the supervision of cases under treatment, to create conditions conducive to care in prison and at the exit.
\end{abstract}

Keywords: Effect, Medical, Nutritional, Program, Tuberculosis, Treatment, Outcome, Detainees

\section{Introduction}

Combating pulmonary TB is a complex process that requires the treatment of TB cases as well as the identification and treatment of people with latent TB infection [1]. This deadly disease is transmissible and its treatment is very restrictive, with an obligation to take four drugs every day for six to nine months [2]. This combination of antibiotics can cause painful side effects. These constraints discourage those affected, and if strict protocol is not respected, the infectious agent can become resistant, making healing much more difficult and imposing hospitalization. For all these reasons, the fight against tuberculosis is doomed to failure if it does not include a daily support device close to the patient [2]. In prisons, the margin of results obtained with regard to the completion of the treatment and the detection rate is often very wide. This problem is 
universal and encountered in high, middle and low income countries. In low- and middle-income countries, this lack of resources, however, could be so drastic that even the basic needs of prisoners cannot be met, which has a significant impact on the health outcomes of individuals [3]. There is very little published data on TB treatment outcomes in prisons in Cameroon. In this retrospective and cross-sectional study, we want to analyze the effect of a medical hygiene and nutritional program on tuberculosis treatment success rates in Bertoua prison. The purpose is to contribute to the establishment of a more rational control system of this pathology and to better care in prisons in low- and middle-income countries in general. To describe the effect of the program in the Bertoua prison, we chose as a witness, Douala-New-Bell prison, in the Littoral region which does not benefit from this ICRC program. Our interest in these prisons was mainly in the similarity of the conditions of detention and in particular the high occupancy rates compared to the official theoretical reception capacity.

\section{Subjects and Methods}

This is a retrospective and cross-sectional study conducted in two prisons (Bertoua and Douala) among detainees diagnosed with pulmonary tuberculosis during the period from $1^{\text {st }}$ January to $31^{\text {st }}$ December 2018.

\subsection{Interventions}

Since 2015, the Bertoua prison has been continuously benefiting from the ICRC's multifaceted interventions, namely: the prevention and treatment of malnutrition, the facilitation of access to care for all detainees, particularly patients suffering from tuberculosis, supply of essential drugs, donations of catering utensils, provision of water. Unlike the Douala prison which does not benefit from this program but only sporadic food aid associations, individuals etc.

\subsection{Data Source}

We used data from medical diagnoses of incarceration on admission to prison and NTCP data that included both passive (symptomatic sputum microscopy) and active (at-risk), such as People Living with HIV, contacts of TB cases in general). The latter was based on clinical data (cough greater than two weeks \pm general or pulmonary signs), sputum culture with the methods GeneXpert and Ziehl Neelsen recommended by the NTCP. A structured data collection has been prepared and used to extract data on the characteristics of TB patients and treatment outcomes. They were used to record all information for the treatment and monitoring of TB patients. These data were completed by in-depth interviews. The Institutional Research Ethics Committee for Human Health at the University of Douala has approved the research protocol.

\subsection{Statistical Analyzes}

Rates were calculated with $95 \%$ confidence intervals (95\% CI) for a p-value $<0.05$ (p) of significance for all indicators. Fisher and Student statistical tests were performed to compare the sociodemographic variables and averages of the two sites. Associations between successful TB treatment outcomes and independent variables were assessed using logistic regression. The outcome was categorized as successful (cured and treatment completed) and unsuccessful (default, failure, death and In these cases, OR (Odds Ratio) values have been added which correspond to a relative risk estimate; this to further strengthen the test results. The results are expressed as mean \pm standard deviation (for quantitative variables) or percentage (for qualitative variables). Statistical analyzes were performed using SPSS 21.0 (Statistical Package for Social Sciences, Chicago, IL, United States). -United).

\section{Results}

\subsection{TB Detainees}

In the two prison populations studied (Bertoua and Douala), the 27 and 79 TB prisoners were of Cameroonian nationality mainly (100\% and 92.6\%); male (100\% and $97.5 \%)$. The average ages were around $29 \pm 3.24$ years and $31 \pm 1.86$ years, less than $14.80 \%$ and $8.90 \%$ minors and 23 and 51 new cases $(85.20 \%$ and $64,55 \%)$. The distribution of nationalities in the two prisons seems to be the same according to the independence test carried out $(\mathrm{p}=0.063)$; the same is true for the distribution of age groups $(p=0.287)$ and for the type of case observed $(p=0.076)$. There would therefore be great similarities between tuberculous prisoners in Douala prison and Bertoua prison with regard to their age group, the type of case encountered and even more so with regard to $\operatorname{sex}(p=1)$. On the contrary, there is a fairly large difference $(p=0.011)$ between the two prisons in terms of time spent before the diagnosis of tuberculosis after their entry into prison (Table 1).

Table 1. General Characteristics of Inmates TB by Prison.

\begin{tabular}{|c|c|c|c|c|c|}
\hline & & & \multirow{2}{*}{ P-value } & \multicolumn{2}{|l|}{ Prison } \\
\hline & & & & Bertoua & Douala \\
\hline \multirow{6}{*}{ Nationality } & \multirow{2}{*}{ Cameroon } & Count & \multirow{8}{*}{0.063} & 25 & 79 \\
\hline & & $\%$ & & 92.6 & 100 \\
\hline & $\mathrm{DCA}$ & Count & & 1 & 0 \\
\hline & KCA & $\%$ & & 3.7 & 0 \\
\hline & Chad & Count & & 1 & 0 \\
\hline & Clra & $\%$ & & 3.7 & 0 \\
\hline \multirow{2}{*}{ Total } & & Count & & $\mathrm{N}=27$ & $\mathrm{~N}=79$ \\
\hline & & $\%$ & & 100 & 100 \\
\hline
\end{tabular}




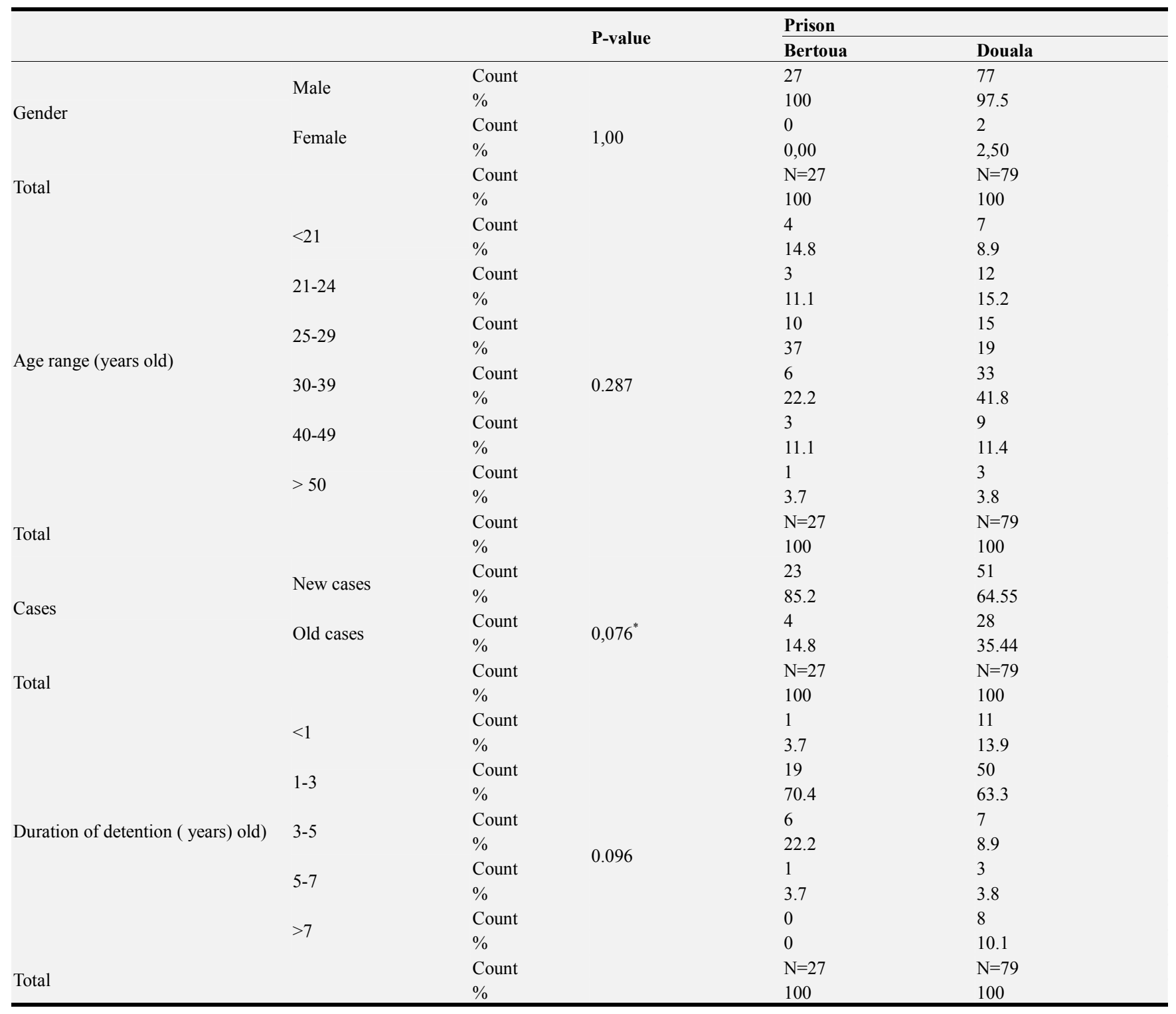

${ }^{*}$ For IC $=90 \%$ (Significant for $\mathrm{p}$-value $<0.1$ )

\subsection{Screening of Tuberculosis}

In both prisons, the diagnosis is essentially biological and symptomatic. Prisoners were not screened systematically, here passive screening of symptomatic subjects is used by microscopic examination of sputum (bacilloscopy). Bacilloscopic confirmation is done in Tuberculosis Diagnosis and Treatment Centers (DTC).

The frequency of screening varied, therefore, according to the cases of suspicion of the physical state of the prisoners. The screening rate varied from prison to prison. The detection rates of TB in symptomatic inmates in 2018 were respectively $5.23 \% \pm 0.061$ and $2.39 \% \pm 0.034$ in Bertoua and Douala respectively $(\mathrm{p}<0.05)$.

The length of detention for the 2 nd quartile of prisoners before the diagnosis of tuberculosis was around 14 months

\pm 4.27 ( $>12$ months) in the Bertoua prison, ranging from 1 to 48 months; and 7 months \pm 5.02 (6-12 months) in Douala prison, varying from 1 to 96 months depending on the prisoners' sentences following the prison sentences (Table 2).

The test showed a difference in TB screening efforts in the two prisons $(p=0.011)$ between TB detainee time intervals after incarceration in the various Bertoua and Douala prisons. It thus appears that in the Bertoua prison the characteristic signs of tuberculosis or the physical state of the patient let the disease show up a little later after the entry of the prisoners than in that of Douala. Despite this difference, there is no concept of delay (eight days or less between incarceration and the result of screening). 
Table 2. Distribution of TB detainees by time before diagnosis in DTCs.

\begin{tabular}{|c|c|c|c|c|c|}
\hline \multirow{2}{*}{\multicolumn{2}{|c|}{ Risk indicator of contagion and screening }} & & \multirow{2}{*}{ P-value } & \multicolumn{2}{|l|}{ Prison } \\
\hline & & & & Bertoua & Douala \\
\hline \multirow{8}{*}{$\begin{array}{l}\text { Time interval for } \\
\text { diagnosing TB after entry }\end{array}$} & \multirow{2}{*}{$<1$ month } & Count & \multirow{10}{*}{0.006} & 1 & 8 \\
\hline & & $\%$ & & 3.7 & 10.1 \\
\hline & \multirow{2}{*}{ 1-6 month } & Count & & 6 & 28 \\
\hline & & $\%$ & & 22.2 & 35.4 \\
\hline & & Count & & 2 & 19 \\
\hline & $6-12$ month & & & 7.4 & 24.1 \\
\hline & & Count & & 18 & 24 \\
\hline & $>12$ month & $\%$ & & 66.7 & 30.4 \\
\hline \multirow{2}{*}{\multicolumn{2}{|c|}{ Total }} & Count & & $\mathrm{N}=27$ & $\mathrm{~N}=79$ \\
\hline & & $\%$ & & 100.0 & 100.0 \\
\hline
\end{tabular}

\subsection{Treatment of Tuberculosis}

In 2018 we recorded 23 and 51 new cases of TB, the rates of patients put on treatment after screening were $100 \%$ in all the two prisons of Bertoua and Douala. However it should be noted that only $37.0 \%$ and $6.6 \%$ of these patients were treated on the same day (Table 3).

Despite the poor performance in both prisons, there is a significant difference $(\mathrm{p}=0.003)$ between the time of treatment after diagnosis in Douala prison and the timing of treatment after diagnosis in the Bertoua prison. The Bertoua prison would therefore be faster in treatment than in Douala.

Table 3. Timing of TB treatment after diagnosis in DTCs in 2018.

\begin{tabular}{|c|c|c|c|c|c|c|}
\hline \multirow{2}{*}{\multicolumn{3}{|c|}{ Indicator of initiation of anti-TB treatment }} & \multirow{2}{*}{ P-value } & \multicolumn{2}{|l|}{ Prison } & \multirow{2}{*}{ Total } \\
\hline & & & & Bertoua & Douala & \\
\hline \multirow{11}{*}{$\begin{array}{l}\text { Timing of } \\
\text { treatment after } \\
\text { diagnosis results }\end{array}$} & \multirow{2}{*}{ Same day } & Count & \multirow{13}{*}{0.004} & 10 & 5 & 15 \\
\hline & & $\%$ & & 37.0 & 6.6 & 14.6 \\
\hline & \multirow{2}{*}{$1^{\text {st }}$ week after } & Count & & 10 & 47 & 57 \\
\hline & & $\%$ & & 37.0 & 61.8 & 55.3 \\
\hline & \multirow{2}{*}{$1^{\text {st }}$ month after } & Count & & 5 & 18 & 23 \\
\hline & & $\%$ & & 18.5 & 23.7 & 22.3 \\
\hline & $2^{\text {nd }}$ month after & $\%$ & & 0.0 & 3.9 & 2.9 \\
\hline & ${ }^{\text {rd }}$ month $a^{2}$ & Count & & 1 & 1 & 2 \\
\hline & 3 month after & $\%$ & & 3.7 & 1.3 & 1.9 \\
\hline & Men then 2 motho for & Count & & 1 & 2 & 3 \\
\hline & More than 3 months atter & $\%$ & & 3.7 & 2.6 & 2.9 \\
\hline \multirow{2}{*}{\multicolumn{2}{|c|}{ Total }} & Count & & 27 & 76 & 103 \\
\hline & & $\%$ & & 100 & 100 & 100 \\
\hline
\end{tabular}

Of the new TB cases recorded in 2018, we recorded 14 and 47 in the cohorts of Q1 and Q2, respectively, under the anti-TB therapeutic regimen, in principle at the end of their treatment for the 6-month protocol as of January 1st, 2019. We had 12 cases $(85.7 \%)$ and 33 cases (70.2\%) that had a therapeutic success (complete treatment and / or cured) as of January 1st, 2019 (Table 4).

Table 4. Treatment completeness and situation of cohort cases for the 1st \& 2nd 2018 to 1 st January 2019 Quarters.

\begin{tabular}{|c|c|c|c|c|}
\hline \multirow{4}{*}{ Treatment results } & \multirow{3}{*}{ Categories } & \multicolumn{2}{|l|}{ Prison } & \multirow{4}{*}{ Comparative proportions } \\
\hline & & Bertoua & Douala & \\
\hline & & No $(\%)$ & No $(\%)$ & \\
\hline & New cases on TB treatment & 14 & 47 & \\
\hline \multirow{2}{*}{ Success of treatment } & Cured $(\%)$ & $11(78.6)$ & $31(66.0)$ & \multirow{2}{*}{$85.7 \% \_70.2 \%$} \\
\hline & Complete treatment $(\%)$ & $1(7.1)$ & $2(4.2)$ & \\
\hline \multirow{4}{*}{ Treatment failure } & "Retreatment (\%) & $1(7.1)$ & $7(14.9)$ & \multirow{4}{*}{$14.3 \% \_29.8 \%$} \\
\hline & Died $(\%)$ & $1(7.1)$ & $2(4.2)$ & \\
\hline & Lost view (\%) & $0(0.0)$ & $2(4.2)$ & \\
\hline & Released (\%) & $0(0.0)$ & $3(6.3)$ & \\
\hline
\end{tabular}

Retreatment $=*$ Relapse, $* *$ Failure, $* * *$ Resumption of treatment ${ }^{\circ}$ Logistic regression test.

*patients who currently have positive microscopic pulmonary tuberculosis who have been declared "ured"or "ompleted treatment"in the past.

** patients in the course of treatment who have positive bacilloscopic examinations during the bacteriological control of the 5th month or later during treatment.

***patients who have been on TB treatment for a month or more and who, having discontinued treatment, present with symptoms of pulmonary tuberculosis and positive sputum tests.

It is clear from the table above that in 2018 the results of reprocessing are $85.7 \%$ successful in Bertoua prison, compared to $70.2 \%$ in Douala prison.
In addition, uncompleted treatment is almost 4 times higher in Douala prison than in Bertoua prison $(p=0.276)$. Also, in the Douala prison there are more unhealed patients 
after treatment than in Bertoua $(\mathrm{p}=0.173)$. There would be more cases of therapeutic failures in Douala prison $(29.8 \%)$ than in Bertoua prison (14.3\%) (Table 5).

Table 5. Proportion of therapeutic failures by site for cohort 1 and 22018 to January 1, 2019.

\begin{tabular}{|c|c|c|c|c|c|c|c|}
\hline \multirow[b]{2}{*}{ Prison } & \multicolumn{7}{|c|}{ Population of prisoners TB } \\
\hline & $\begin{array}{l}\text { TB cases name } \\
\text { (in 2018) }\end{array}$ & $\begin{array}{l}\text { Number of TB cases } \\
\text { being treated as of } \\
1^{\text {st }} \text { January } 2019\end{array}$ & $\begin{array}{l}\text { New and old } \\
\text { cases put on TB } \\
\text { treatment }(\%) \\
\end{array}$ & $\begin{array}{l}\text { Cohort TB detainees } \\
\text { from quarters } 1,2,3 \\
\& 4,2018\end{array}$ & $\begin{array}{l}\text { TB cohort } \\
\text { quarterly } 1 \& 2 \\
2018\end{array}$ & $\begin{array}{l}\text { TB treatment } \\
\text { case not } \\
\text { completed (\%) }\end{array}$ & $\begin{array}{l}\text { TB treatment } \\
\text { cases not } \\
\text { cured }(\%) \\
\end{array}$ \\
\hline Bertoua & 27 & 12 & $27(100)$ & 23 & 14 & $2(14.3)$ & $2(14.3)$ \\
\hline Douala & 79 & 30 & $79(100)$ & 51 & 47 & $14(29.8)$ & $16(34.0)$ \\
\hline OR & & & & & & 3.820 & 4.363 \\
\hline P-value & & & & & & 0.276 & 0.173 \\
\hline
\end{tabular}

$\wedge$ Cases of death are not taken into account

In addition, a retrospective study of cases treated in the DTCs of the two prisons between 2016 and 2018 shows low therapeutic success rates $(50 \%)$ below $85 \%$ (objective of the NTCP) in 2016 and in 2017 before increasing. (86\%) in 2018. On the other hand, for this last year the DTC of the Douala prison knows a fall of this rate $(70 \%)$, contrasting with its performances $(87 \%$ and $95 \%)$ registered previously in 2016 and 2017. It is important to observe the low proportion of cases to be treated in Bertoua prison $(7 \%)$, unlike the Douala prison (17\%) in 2018. Let us also note these high rates of patients released before the end of treatment (35\%). \% and 31\%) in Bertoua prison in 2016 and 2017 and for whom we have not had evidence of transfers to DTCs outside the prison as treatment results (Table 6).

Table 6. Completeness of treatments and general situation of cases from 2016 to 2018 in the DTCs.

\begin{tabular}{|c|c|c|c|c|c|c|}
\hline \multirow{2}{*}{ Indicators of treatment follow-up } & \multicolumn{3}{|c|}{ DTC of Bertoua prison } & \multicolumn{3}{|c|}{ DTC of Douala prison } \\
\hline & 2016 & 2017 & $\mathbf{2 0 1 8}^{2}$ & 2016 & 2017 & $2018^{2}$ \\
\hline Number of cases on treatment TB & 165 & 134 & 27 & 52 & 59 & 79 \\
\hline Cured $(\%)$ & $133(81)$ & $96(72)$ & $11(79)$ & $38(75)$ & $49(83)$ & $31(66)$ \\
\hline Complete treatment (\%) & $7(4)$ & $11(8)$ & $3(7)$ & $6(12)$ & $7(12)$ & $2(4)$ \\
\hline Retreatment (\%) & $0(0)$ & $0(0)$ & $1(7)$ & $1(2)$ & $0(0)$ & $7(15)$ \\
\hline Death $(\%)$ & $3(2)$ & $3(2)$ & $1(7)$ & $2(3)$ & $0(0)$ & $2(4)$ \\
\hline Lost view (\%) & $17(10)$ & $18(13)$ & $0(0)$ & $1(2)$ & $1(2)$ & $2(4)$ \\
\hline
\end{tabular}

${ }^{2}$ Cohorts of quarters 1 and 2 in 2018

\section{Discussion}

Interruptions in treatment and nonobservance appear to be the result of culture in prison. Malnutrition, logistics in prison, negligence, lack of commitment to improve conditions and care by authorities and prison staff have presession on many other factors.

This study comes in a context where detention conditions in Cameroonian prisons are under the spotlight of several media and civil society organizations both within the country and internationally.

To our knowledge, this is the first study to have evaluated the effect of the ICRC's medical, hygiene and nutritional program on tuberculosis treatment outcomes since its launch in 2015 in Bertoua prison. It contributes to the improvement of the Minimum Rules of Incarceration (RMI) and to a limitation of new cases of tuberculosis among prisoners. It is therefore timely in the resolution of this major public health problem both in the general population and in prisons.

In fact, Cameroon has been classified among the 30 countries with the highest rates of tuberculosis [4]. However, prisons are hot spots of infection and the risk of TB transmission in overcrowded prisons is further enhanced by malnutrition, which has been identified as a key pillar in reducing immune resistance. This deficit combined with poor hygiene and limited access to adequate medical care is a major public health problem.

In 1993, Human Rights Watch's Global Prison Report [5] noted that the majority of prisoners in the world were "confined to unsanitary conditions and corruption, without adequate food or medical care, with little activity. or nothing to do, and in circumstances where the violence of other inmates, guards or even both is a constant threat. " A decade later, the 2013 US State Department Report on International Prison Conditions stated: "The majority of prison systems in the world do not comply with all United Nations minimum standards." acting on the treatment of detainees. In some countries, relevant international obligations and standards are deliberately ignored. " The report has highlighted universal problems that threaten the health and life of prison populations: overcrowding, lack of hygiene and / or medical facilities, and denial of care [6].

The re-emergence of TB and the rapid spread of MDR-TB in prisons around the world has recently led several human rights bodies to express their deep concern over the state of the world's prisons and to question whether the health of prisoners is in line with international human rights standards. The fact that these standards are not respected is one of the main drivers of the TB epidemic in prisons and communities around the world [7]. 
In principle, the penitentiary administration is responsible for providing adequate food for all prisoners within its institution. Since not all nutritional requirements can be met by one meal, two minimum meals must be served each day. The energy content of the diet received by the prisoners must be at least 2,400 kcal. However, this can be adapted according to the profiles of the prisoners and their physical activities of age and sex [8].

Regarding the profile, in this study, as in almost all of the most represented prison populations are men who are generally the most infected as evidenced by these results with $100 \%$ and $97.5 \%$. In a survey of the National Institute of Statistics (INS) on the penal chain in Cameroon in 2014, we had less than $2 \%$ of women and girls. Globally, only 6.5 per cent of the world's prisoners are women, and this figure represents a five-fold increase in the female prison population over the last 15 years [9]. Data on TB among female prisoners is insufficient. However, a study in Brazil found that time spent in prison increases the risk of contracting TB for women [10]. For example, in Zambia, TB screening rates among female prisoners are lower than those of their male counterparts $[11,12]$. The proportion of minors (less than $14.80 \%$ and $8.90 \%$ ) in these prisons has increased compared to the national average which according to this report of the INS in 2014 in Cameroon estimated at 2.3\%.

In addition, the median duration of detention before the diagnosis of tuberculosis was around 14 months \pm 4.27 ( $>12$ months) in Bertoua prison, and 7 months \pm 5.02 (6-12 months) in Douala prison. The difference in time between the two sites could be explained by the medical, hygiene and nutrition program which has reduced the risk of contraction of tuberculosis. This makes it possible to conclude $(p=0.006)$ that long stays constitute a risk factor for contraction of this disease.

As for the screenings practiced in these two prisons there is no notion of delay since it is not systematic. This, while TB can be successfully treated if the screening takes place on time. In ideal situations, it must be done within eight days or less between incarceration and the result of screening [13].

In both sites, a lack of human and material resources was reported by medical teams including in Douala prison. This problem has been felt in the detection rates of TB in symptomatic prisoners in 2018 estimated at 5.23\% and $2.39 \%$ in Bertoua and Douala prisons, respectively. This frequency of screening thus varied according to the cases of suspicion of the physical state of the prisoners, which are difficult to practice with high rates of incarceration. This rate, even if it is higher and significant $(p=0.006)$ in Bertoua prison compared to that of Douala, remains low in both cases compared to the 90-90-90 and NTCP goals [14, 15].

It should also be noted that in Cameroonian prisons, TB / HIV testing is a joint activity among groups of at-risk prisoners, such as people living with HIV (PLHIV) and vulnerable people in general. As a result, there is a need for increased human resource efficiency, improved capacity of prison medical staff, and efforts by prison authorities to prevent the spread of TB in prisons [16].
In addition, WHO recommends two approaches for screening in prisons: active and passive. Active screening must occur both at the admission of prisoners in prison and throughout the period of imprisonment, during which prison populations should regularly be screened for TB $[17,18]$.

When the prisoner is admitted to prison, a medical examination that is respectful of the incarcerated individual must be carried out and include a TB screening using questionnaires, a lung radio, a tuberculin skin test (TST).) and a gamma interferon release test (IGRA), or even a combination of these methods [18, 19].

In the two prisons targeted in this study, medical examinations for incarceration were done, as was TB screening, but passively. Despite the efforts of various actors, there was no chest X-ray, it was done outside their premises, requiring escorts by security guards. The main constraint is the lack of X-ray equipment and an imaging specialist in these facilities.

Of all the above, systematic screening for pulmonary TB should be initiated by the medical teams in consultation with the NTCP and the administration before any admission to prison and not only in case of suspicion as is currently the case.

With regard to the treatment of tuberculous prisoners whose antibiogram shows no resistance, the treatment of choice consists of a combination of four drugs during the initial phase (isoniazid, rifampicin, pyrazinamide and ethambutol) and two drugs during the continuation phase (isoniazid and rifampicin) [18].

$85.7 \%$ and $70.2 \%$ of TB prisoners experienced therapeutic

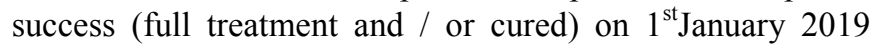
respectively in the Bertoua and Douala detention centers. The goal of the program, which is to "cure at least $85 \%$ of TPM + patients diagnosed with standardized treatment", was achieved in the first detention center. WHO target for TB treatment outcome $\geq 90 \%$ success rate $[4,15]$.

In Cameroon, in the population of detainees suffering from pulmonary tuberculosis in 2017 in general, treatment was only completed in $63 \%$ of prisoners whose tuberculosis had been diagnosed during their detention [9]. These disappointing results illustrate that more needs to be done to ensure that treatment is completed successfully for TB patients in detention. It is therefore a priority for each of them to benefit from treatment supervision as soon as it is introduced. This can be provided by the medical service of the prison, possibly in collaboration with prison officials.

In order to optimize the treatment outcomes of tuberculosis prisoners, WHO advises that every patient who is imprisoned be supervised while taking DOT (Directly Observed Therapy). The NTCP as the body in charge of the fight against this disease in Cameroon offers free of charge these drugs to patients throughout the national territory through 260 DTC including those prisons. Its goal is to reduce Tuberculosis-related morbidity and mortality based on the DOTS strategy $[2,20]$.

However, the supervision of the prisoner's treatment, which is already particularly difficult in prison alone, is not 
enough. From the lived experience, several inmates generally interrupt these treatments because of the lack of food or simply because of an insufficient daily food ration. Indeed, malnutrition can also be the cause or consequence of other diseases. It can cause diseases by altering the functioning of the immune system. Malnutrition can also be a consequence of disease (and not simply due to undernourishment), as many diseases result in increased nutrient requirements of the body, while impairing its ability to utilize these nutrients (especially tuberculosis, AIDS, dysentery, cancer and severe infections).Thus, the low number of old cases of TB in Bertoua prison (14.80\%) unlike the Douala prison (35.44\%) is therefore probably attributable to therapeutic failures mainly due to malnutrition. Since the results of treatment that failed were 2 cases (14.3\%) in Bertoua prison and 14 cases $(29.8 \%)$ in Douala prison in quarters 1 and $22018(\mathrm{p}<0,05)$. These low therapeutic success rates in 2016 and 2017 in Bertoua prison are mainly related to the high rates $(35 \%$ and $31 \%$ ) of patients released but still on treatment.

Moreover, the follow-up of prisoners on their release is a major difficulty for the NTCP, especially for patients who are primarily infected in prison. In Douala prison in 2018 we recorded, for all quarters, 8 cases $(10.1 \%)$ of prisoners who left before the end of treatment and for whom we did not have any reference evidence in the registered DTCs.

In addition, in an assessment of the existing collaboration between health services inside and outside prisons, it has been shown in the US that not being informed in a timely manner about the release of tuberculous prisoners was the biggest obstacle to the continuity of treatment [21].

Similarly, at the time of arrest and detention, some people who are about to be incarcerated have already been treated for $\mathrm{TB}$ in the community. Similarly, while receiving treatment in prison, a series of punitive measures and / or logistical measures, such as isolation, transfers between prisons and other practices, could interfere with treatment. When people with TB are released from prison, their treatment regimen may also be interrupted and may not even be available in the communities where they live [22-25].

In order to prevent prisoners from interrupting their TB treatment at the time of release, it is essential that a nurse or doctor contact them while they are still in the penitentiary system. The objective is to inform them of the modalities to follow to continue taking anti-tuberculosis drugs outside the prison.

Closer articulation between prison care teams and tuberculosis teams in the general population, resulting in particular in their medical and social consultation with tuberculosis prisoners, should improve screening. around each case and follow-up on leaving prison. This is all the more important in a prison environment where this approach comes up against numerous constraints. Care must also be taken to ensure the continuity of this treatment after their release by informing them of the places where they can go in case of difficulties of access to care.

Ensuring continuity of treatment is key to the success of prison TB prevention and control programs. Thus, it is essential that if an individual with TB also takes drugs, that he or she be given substitution treatment to ensure adherence. However, such treatment is often unavailable in prisons [26].

It is also essential to focus on strengthening the links within the penitentiary system and creating medical records that can accompany the person with TB from one place to another.

Former prisoners may not want to continue treatment for a variety of reasons; however, connecting them with health authorities and community-based support organizations in the community is crucial to facilitate continued treatment and success.

Finally, there is also the role of the medical and paramedical staff who are primarily responsible for the treatment of prisoners and the care environment.

Regarding the medical and paramedical staff in these prisons studied, not all categories of professionals are really represented. In fact, there is a lack of specialists in the management of TB (pneumology, infectious diseases, medical imaging, etc.) for care and services considered to be of capital importance in prisons. In both sites, the interviewees believe that they are understaffed, with a high workload and often unmotivated. They therefore called for a return of the German International Development Cooperation Agency "GiZ TB Prison" program, which in the past had a motivating system that provided more logistical and financial resources to track more TB patients and better patient supervision.

\section{Conclusion}

Although in 2016 and 2017 we cannot conclude because of the high rate of patients released before the end of treatment, the therapeutic success rate TB in 2018 in Bertoua prison is probably attributable to this program because of the food ration daily improved among the prisoners unlike the Douala prison. For better control of $\mathrm{TB}$, this program should be generalized to other prisons with, in addition, the lightening of the penal procedures of the prisoners, the use of the alternative punishments, the regular screenings of the inmates contacts TB. In addition, TB inmate treatment supervision can be enhanced by scaling up DTC resources and their performance motivation following Performance based Financing (PBF) practices in all prisons.Further studies are urgently needed to determine post-release cure rates for prisoners, given the undeniable links between prison TB rates and the general population. We already propose a solution through the scheme to track and treat released prisoners that we propose in the project Relay for TB treatment (R4T).

\section{Authorship}

The authors Mr. LINJOUOM NCHOUTPOUEN Abdou Aziz, Pr. ASSOB NGUEDIA Jules Clément, Pr. CHICHOM MEFIRE Alain, Dr. BESSONG Joseph, Pr. NJAJOU TCHIKAMGOUA Omer were involved in the concept and design of this study, collection, analysis and interpretation of data and the final drafting, revising and approval of the manuscript for submission to the Central African Journal of Public Health. Literature search was 
done by Mr. LINJOUOM NCHOUTPOUEN Abdou Aziz. We take responsibility for the integrity of this work as a whole from conception to publication and give the rights to the corresponding, Mr. LINJOUOM NCHOUTPOUEN Abdou Aziz author to make necessary changes as per the request of the journal, do the rest of the correspondence on our behalf and he will act as the guarantor for the manuscript.

\section{Source of Support}

No support in the form of grant was received for this study and no conflict of interest between the authors.

The purpose of this article is not to produce exhaustive information on health indicators in targeted penitentiaries. It's all about starting a study that will improve prison health systems in high-income countries similar to Cameroon's.

To achieve this, the prisons and the prison population, the Regional Delegations of the Penitentiary Administration of the targeted regions, the NTCP were put to use to inform the data from the prisons.

\section{Acknowledgements}

1. To the team of the Faculty of Health Sciences of the University of Buea (South-West Cameroon) for the guidance provided in the drafting of the research protocol. It is precisely: Pr. ASSOB NGUEDIA Jules Clément, Pr. CHICHOM M. Alain, Dr. BESSONG Joseph, and Pr. NJAJOU T. Omer.

2. To the Regional Delegates of the Penitentiary Administration of the Littoral and Eastern Regions who authorized the research within these penitentiary establishments.

3. To the Medical Directors and staff of the prisons of New-Bell Douala and Bertoua who contributed to the compilation of key data for the writing of this article, and in particular to the General Manager of the prisons Mr. DJANTIN, the IPP MBE Scholastique and the GPPs NJOYA Ebénézer.

4. To Mr. Dublis NGUEFACK of the NTCP for the provision of various reports.

5. To the Regional Delegate of Public Health of the East, Dr. MINTOP Anicet for the facilities of contact with the ICRC team in Bertoua Prison.

\section{References}

[1] Nicole Hanssen. fight against tuberculosis: southern health programs in Mali and Madagascar. Quarterly Info [Internet]. March 2019 [cited April 4, 2019] (No. 121, Health South): 1. Available on: www.santesud.org.

[2] Systematic Review of Tuberculosis Treatment Studies. Center for the Development of Good Practices in Health [Internet]. [cited March 28, 2018]; 1\&4. Available on: www.cdbph.org.

[3] Lack of resources for prisons is having a severe impact on the lives of millions of detainees. [Internet]. Geneva: International Committee of the Red Cross; 2014 [cited Oct. 25, 2018]. Available on: https://www.icrc.org/en/document/annualconference-international-corrections-and-prisons-associationicpa.

[4] Global AIDS Update. [Internet]. WHO, cited by the report of UNAIDS; 2017 [cited sept. 20, 2018]. Available on: http://www.unaids.org/sites/default/files/media_asset/Global AIDS_update_2017_en.pdf.

[5] The Human Rights Watch global report on prisons. [Internet]. New York: Human Rights Watch; 1993 [cited oct. 25, 2018]. Available on: (https://www.hrw.org/ report/1993/06/01/human-rights-watch-global-reportprisons).

[6] Report on international prison conditions. [Internet]. Washington, DC: U.S. Department of State; 2013 [cited oct. 25, 2017]. Available on: (http://www.state.gov/j/drl/rls/209944.htm)

[7] Lines R. The right to health of prisoners in international human rights law. Int J Prison Health. 2008.

[8] Prison health, a practical guide. International Committee of the Red Cross (ICRC) [Internet]. jan. 2017 [cited feb. 10, 2018]. Available on: www.cicr.org

[9] Global prison trends 2015. [Internet]. London: Penal Reform International; 2015 [cited oct. 25, 2017]. Available on: (http://www.penalreform.org/resource/global-prison-trends2015/)

[10] Ferreira MMC, Ferrazoli L, Palaci M, Salles PS, Medeiros LA, Novoa P, et al. Tuberculosis and HIV infection among female inmates in São Paolo, Brazil: a prospective cohort study. J Acquir Immune Defc Syndr Hum Retrovirol [Internet]. 1996 [cited feb. 22, 2018]; Available on: (http://journals.lww.com/jaids/Fulltext/1996/10010/Tuberculo sis_and_HIV_Infection_Among_Female.9.aspx).

[11] Unjust and unhealthy. [Internet]. New York: Human Rights Watch; 2010 [cited feb. 22, 2018]. Available on: (https://www.hrw.org/report/2010/04/27/unjustandunhealthy/hiv-tb-and-abuse-zambian-prisons.

[12] Todrys KW, Amon JJ. Health and human rights of women imprisoned in Zambia. BMC Int Health Hum Rights. 2011.

[13] N. Koffi, A. K. Ngom, A. Séka, N. Kouassi, D. Fadiga. Bacilliferous pulmonary tuberculosis in prison: our experience at the penal camp of Bouaké, Ivory Coast. 1997.

[14] Report on key prisoners [Internet]. Geneva, Switzerland: Global Fund to Fight AIDS, TB \& Malaria; 2015 nov [cited march 15, 2018]. Available on: www.stoptb.org.

[15] Report of the National Tuberculosis Program. Yaounde: MINSANTE/NTCP; 2016, 2017 and 2018.

[16] Internship report of ENAP students in Buéa at the Bertoua Central Prison. Bertoua Central Prison; 2018 p. 21.

[17] Colleen D, Caoimhe S, Farihah M, Jacob C, James Ayre. Case Study on Key Populations, Prisoners [Internet]. Geneva: International Committee of the Red Cross; 2016 [cited 4 Apr. 2018] p. 10. Available on: https://www. icrc.org/en/document/ annual-conference-international-corrections-and-prisonsassociation-icpa. 
[18] Prisons and health. Copenhagen: WHO Regional Office for Europe. 2014 [cited 25 oct. 2018]; Available on: http://www.euro.who.int/data/assets/pdf fle/0005/249188/Pris ons-and-Health.pdf.

[19] Reid SE, Topp SM, Turnbull ER, Hatwiinda S, Harris, JB, Maggard KR, et al. Tuberculosis and HIV control in subSaharan African prisons: "thinking outside the prison cell." $\mathrm{J}$ Infect Dis. 2012.

[20] Bone A, Aerts A, Grzemska $M$ et al. Tuberculosis control in prisons. A manual for programme managers. WHO/CDS/TB/. 2000 .

[21] Lobato M, Roberts C, Bazerman L, Hammett T. Public health and correctional collaboration in tuberculosis control. Am J Prev Med. 2004; (27 (2): 112-117).

[22] Biadglegne F, Rodloff AC, Sack U. Review of the prevalence and drug resistance of tuberculosis in prisons: a hidden epidemic. Epidemiol Infect. 2015.
[23] Prisons and health. WHO Regional Office for Europe [Internet]. 2014 [cited, Oct. 25, 2015]. Available on: (http://www.euro.who.int/ data/assets/pdf fle/0005/249188/ Prisons-and-Health.pdf).

[24] Baussano I, Williams BG, Nunn P, Beggiato M, Fedeli U, Scano F. Tuberculosis incidence in prisons: a systematic review. PLoS Med. 2010.

[25] Reyes H. Pitfalls of TB management in prisons. 2007. Available on: (https://www.icrc.org/eng/resources/documents/article/other/tu berculosis-article-220307.htm, visited on Oct. 25, 2018).

[26] Treatment and care for injecting drug users with HIV infection: a review of barriers and ways forward. Lancet. 2010 . 